A C G

publications

Rec. Nat. Prod. 12:1 (2018) 101-106

records of natural products

\title{
Antioxidant and Neuroprotective Activity of the Aerial Parts of Seven Eragrostis Species and Bioactive Compounds from E. japonica
}

\author{
Chae Sun $\mathrm{Na}^{\oplus 1,2^{*}}$, Min Ju Lee ${ }^{\oplus 1}$, Seong Su Hong ${ }^{\oplus 3}$, Yun-Hyeok Choi ${ }^{\oplus 3}$, \\ Jae-Eun Lee $^{\oplus 4}$, So-Young Park ${ }^{\oplus 4}$, Yong Ho Lee ${ }^{\oplus 5}$ and Sun Hee Hong ${ }^{\oplus 5}$ \\ ${ }^{1}$ Institute of Ecological Phytochemistry, Department of Plant Life and Environmental Science, Hankyong \\ National University, Anseong 456-749, Gyeonggi-do, Republic of Korea \\ ${ }^{2}$ Institut für Botanik, Leopold-Franzens-Universität-Innsbruck, Sternwartestraße 15, 6020 \\ Innsbruck, Austria \\ ${ }^{3}$ Bio-Center, Gyeonggi Institute of Science \& Technology Promotion, Suwon 16229, \\ Republic of Korea \\ ${ }^{4}$ Laboratory of Pharmacognosy, College of Pharmacy, Dankook University, Cheonan 330-714, \\ Republic of Korea \\ ${ }^{5}$ Seed bank of Wild Resource Plants, School of Life Sciences and Biotechnology, Korea University, \\ Seoul 136-701, Republic of Korea
}

(Received April 07, 2017; Revised July 20, 2017; Accepted July 22, 2017)

\begin{abstract}
The main purpose of this study was to evaluate the antioxidant and neuroprotective activities in the aerial parts of seven Eragrostis species (Poaceae) and to find antioxidant or neuroprotective compounds from the most active species. The total phenolic content (TPC), total flavonoid content (TFC), 1,1-diphenyl-1-picrylhydrazyl radical scavenging activity (DPPH RSA), total antioxidant capacity (TAC), and neuroprotective activity against amyloid beta peptide induced toxicity in PC12 cells were measured in the methanol extracts of the aerial parts of E. ferruginea, E. cilianensis, E. minor, E. multicaulis, E. pilosa, E. japonica, and E. curvula collected from June to August 2013 . All species showed antioxidant or neuroprotective activities and, among them, E. japonica was the most active species to isolate antioxidant or neuroprotective compounds, because it was found to show both the highest TPC (10.63 \pm 0.31 $\mathrm{mg} / \mathrm{g})$ and TFC $(2.83 \pm 0.06 \mathrm{mg} / \mathrm{g})$ values, as well as TAC $(11.34 \pm 0.80 \mathrm{mg} / \mathrm{g})$ and DPPH RSA $(47.07 \pm 2.81$ $\mu \mathrm{g} / \mathrm{mL})$, with the second-highest neuroprotective value $(23.0 \mu \mathrm{g} / \mathrm{mL})$. Three known compounds were isolated from $E$. japonica by the bioassay guided approach and these were identified as isoorientin, isovitexin, and caffeic acid that have antioxidant and neuroprotective activities.
\end{abstract}

Keywords: Eragrostis species; Eragrostis japonica; antioxidant activity; neuroprotective activity. C 2017 ACG Publications. All rights reserved.

\section{Plant Source}

The aerial parts of E. ferruginea, E. cilianensis, E. minor, E. multicaulis, E. pilosa, E. japonica, and E. curvula were collected from June to August 2013 throughout South Korea. The plants were identified by

\footnotetext{
*Corresponding author: E- Mail:chaesun.na@uibk.ac.at (C.S. Na), Phone +43-660-6829-208.
} 
Prof. Byeung-Hoa Kang (Seed Bank of Wild Resource Plants, Korea University) Voucher specimens (\#EA20130601-EA20130607) were deposited in Seed Bank of Wild Resource Plants of Korea University.

\section{Previous Studies}

Several previous reports have proved the potential of Eragrostis species as natural resources for a crude drug and dietary health supplement. The methanol (MeOH) extracts from the flour of E. tef and E. tef varieties showed antioxidant activity using the 1,1-diphenyl-1-picrylhydrazyl radical scavenging activity (DPPH RSA) [1-2]. The hexane extract of $E$. viscosa presented moderate molluscicidal activity against the snail Biomphalaria glabrata and 4 diterpenoids were isolated from the extract [3]. Several triterpenoids and diterpenoids were isolated from the roots of E. ferruginea that had been used to treat cancer and diabetes [4]. Penolic compounds were also isolated from the aerial parts of E. ferruginea, specifically, tricin, ageconyflavone A, nectandrin B, and 4-ketopinoresinol, all of which showed neuroprotective activity in PC12 cells against amyloid beta peptide (Aß)-induced toxicity, which is a major contributor to Alzheimer's disease pathology [5]. However, no reports are available that would to demonstrate the antioxidant or neuroprotective activities in the extracts of seven Eragrostis species, E. ferruginea, E. cilianensis, E. minor, E. multicaulis, E. pilosa, E. japonica, and E. curvula.

\section{Present Study}

Extraction and compounds isolation: The aerial parts of Eragrostis species were air-dried and powdered in a mill. Powdered samples $(2.0 \mathrm{~g})$ were extracted by gentle agitation in $\mathrm{MeOH}$ for 1 week at room temperature to test the total phenolic content (TPC), total flavonoid content (TFC), total antioxidant capacity (TAC), free radical scavenging activity, and neuroprotective activity. Among the $\mathrm{MeOH}$ extracts of Eragrostis species, Eragrostis japonica showed the most significant activity in this study (Table $1 ; 2$ ) and was further investigated to separate compounds by bioassay guided approach. The air-dried powder of aerial parts of E. japonica $(110.0 \mathrm{~g})$ were extracted three times with $\mathrm{MeOH}$. The $\mathrm{MeOH}$ extract $(11.1 \mathrm{~g})$ was dissolved in water and then partitioned with n-Hexane. The aqueous layer was separated with XAD-2 column chromatography using water of various $\mathrm{pH}$ levels and $\mathrm{MeOH}$ to afford 4 fractions (F01-F04). Antioxidant activity was measured in each fraction and active fractions used for isolation of compounds. Fraction F04 (MeOH phase, $0.92 \mathrm{~g}$ ) was re-chromatographed by preparative paper chromatography using the BAW solvent (upper phase, $\mathrm{BuOH}$ : Acetic acid: Water = 4:1:5), dividing in 9 fractions (F05-F13). Fraction F08 (196 mg) was passed over a column containing Sephadex LH-20 gel using 70\% MeOH as eluent, resulting in 5 fractions (F14-F18). Compounds $1(1.2 \mathrm{mg})$ and $2(2.9 \mathrm{mg})$ were isolated from F17 and compound $\mathbf{3}(2.0 \mathrm{mg}$ ) was separated from F18 by preparative HPLC (column: Agilent Kromasil 100-5$\mathrm{C} 18,5 \mu \mathrm{m}, 21.2 \times 250 \mathrm{~mm}$ i.d., at flow rate $=8 \mathrm{ml} / \mathrm{min}$ ) using $20-35 \% \mathrm{ACN}$ and $30-65 \% \mathrm{MeOH}$ as solvent systems, respectively.

Antioxidant activity assessment: TPC was determined using the Folin-Ciocalteu method [6] and TFC was measured using the colorimetric aluminium chloride $\left(\mathrm{AlCl}_{3}\right)$ method [7]. TAC was assessed with the phosphomolybdenum reduction assay [8] and free radical scavenging activity was determined using DPPH [9]. TPC and TAC were expressed as mg gallic acid equivalent (GAE)/g of dry weight (DW) and TFC was expressed as mg quercetin equivalent $(\mathrm{QE}) / \mathrm{g}$ of DW. $\mathrm{IC}_{50}$ values were used for DPPH RSA and it was defined as the amount of antioxidant required to reduce the initial DPPH radical concentration $(\mu \mathrm{g} / \mathrm{mL})$ by $50 \%$. Ascorbic acid was used as a reference compound for DPPH RSA.

Neuroprotective activity assessment: The $A \beta_{25-35}$ used in the present study was pre-aggregated prior to use, because $A \beta$ oligomers are more toxic to neurons than $A B$ monomers (soluble form) or fibrils [10]. $A \beta_{25-35}$ (1 mg; Bachem California Inc.) was dissolved in $1 \mathrm{~mL}$ of Dulbecco's Modified Eagle's Medium (DMEM, Gibco) and incubated in a $37^{\circ} \mathrm{C}$ water bath for 3 days to induce aggregation. Aggregated $\mathrm{A} \beta_{25-35}$ was diluted to $100 \mu \mathrm{g} / \mathrm{mL}$ and stored at $-70^{\circ} \mathrm{C}$ until use. Rat PC12 pheochromocytoma cells were obtained from the American Type Culture Collection (ATCC) and maintained in DMEM supplemented with 15\% horse serum (Gibco) and 5\% fetal bovine serum (Gibco) at $37^{\circ} \mathrm{C}$ under $5 \% \mathrm{CO}_{2}$. The cells used for 
experiments were in the exponential growth phase and exponentially growing PC12 cells $\left(4 \times 10^{4}\right.$ cells per well) were plated in 96-well tissue culture plates. The cells were then pretreated with various concentrations $(100,20$, or $4 \mu \mathrm{g} / \mathrm{mL})$ of $\mathrm{MeOH}$ extracts from collected Eragrostis species with rosmarinic acid as a positive control. One hour later, $A \beta$ aggregates $(10 \mu \mathrm{M})$ were added to the pretreated cells and incubated for additional $24 \mathrm{~h}$. For further analysis, the cells were treated with 3-(4,5-dimethylthiazol-2-yl)2,5-dimethyltetrazolium bromide, MTT solution ( $10 \mu \mathrm{L}$ per well, $5 \mathrm{mg} / \mathrm{mL}$ stock solution) for $3 \mathrm{~h}$ at $37^{\circ} \mathrm{C}$, followed by lysis overnight at $37^{\circ} \mathrm{C}$ in $100 \mu \mathrm{L}$ of lysis buffer. The optical density of the resulting solutions was measured colorimetrically at $590 \mathrm{~nm}$ using a microplate reader. Dose-response curves were plotted for each extract and results were expressed as $\mathrm{ED}_{50}$ values, which were defined as the concentration $(\mu \mathrm{g} / \mathrm{mL})$ required to achieve $50 \%$ cell viability.

Statistical analysis: SAS 9.2 software (SAS Institute Inc.) was used to find the correlation coefficient (R) by the Pearson correlation and significant differences $(p<0.05)$ were established by one-way analysis of variance (ANOVA) with a post hoc least significant difference test.

Table 1. Total phenolic content (mg gallic acid equivalent/g of dry weight), total flavonoid content (mg quercetin equivalent/g of dry weight), total antioxidant capacity (mg gallic acid equivalent/g of dry weight), and DPPH free radical scavenging activity $\left(\mathrm{IC}_{50}, \mu \mathrm{g} / \mathrm{mL}\right)$ in methanol extracts from the aerial parts of seven Eragrostis genus.

\begin{tabular}{lcccc}
\hline $\begin{array}{l}\text { Eragrostis } \\
\text { species }\end{array}$ & Total phenolics & Total flavonoids & $\begin{array}{c}\text { Total antioxidant } \\
\text { capacity }^{\mathrm{b}}\end{array}$ & $\begin{array}{c}\text { DPPH radical } \\
\text { scavenging activity }^{\mathrm{a}}\end{array}$ \\
\hline E. ferruginea & $4.14 \pm 0.24^{\mathrm{d}}$ & $1.25 \pm 0.08^{\mathrm{cd}}$ & $7.96 \pm 0.50^{\mathrm{bc}}$ & $60.86 \pm 1.64^{\mathrm{d}}$ \\
E. cilianensis & $4.02 \pm 0.07^{\mathrm{d}}$ & $0.83 \pm 0.03^{\mathrm{e}}$ & $11.39 \pm 1.46^{\mathrm{a}}$ & $>100^{\mathrm{f}}$ \\
E. minor & $3.26 \pm 0.08^{\mathrm{e}}$ & $0.92 \pm 0.02^{\mathrm{e}}$ & $6.04 \pm 0.71^{\mathrm{c}}$ & $>100^{\mathrm{f}}$ \\
E. multicaulis & $4.76 \pm 0.03^{\mathrm{c}}$ & $1.93 \pm 0.01^{\mathrm{b}}$ & $5.41 \pm 0.52^{\mathrm{c}}$ & $85.70 \pm 0.68^{\mathrm{e}}$ \\
E. pilosa & $4.05 \pm 0.10^{\mathrm{d}}$ & $1.14 \pm 0.02^{\mathrm{d}}$ & $9.26 \pm 0.88^{\mathrm{ab}}$ & $>100^{\mathrm{f}}$ \\
E. japonica & $10.63 \pm 0.31^{\mathrm{a}}$ & $2.83 \pm 0.06^{\mathrm{a}}$ & $11.34 \pm 0.80^{\mathrm{a}}$ & $47.07 \pm 2.81^{\mathrm{b}}$ \\
E. curvula & $6.05 \pm 0.20^{\mathrm{b}}$ & $1.32 \pm 0.01^{\mathrm{c}}$ & $11.77 \pm 1.38^{\mathrm{a}}$ & $53.13 \pm 2.42^{\mathrm{c}}$ \\
Ascorbic acid & & & & $3.33 \pm 0.06^{\mathrm{a}}$ \\
\hline
\end{tabular}

In each column, common letters indicate values that are not significantly different by one-way analysis of variance, followed by Duncan's multiple range test $(\alpha=0.05)$. Values in the table are means \pm SE. ${ }^{\mathrm{a}} \mathrm{IC}_{50}$ was defined as the amount of antioxidant required to reduce the initial $\mathrm{DPPH}$ free radical concentration by $50 \%$; ${ }^{b}$ reference compound

To establish the antioxidant activity of Eragrostis species, TPC, TFC, TAC, and DPPH RSA of the seven $\mathrm{MeOH}$ extracts were measured (Table 1). E. japonica showed the highest TPC with $10.63 \pm 0.31 \mathrm{mg}$ $\mathrm{GAE} / \mathrm{g}$ of DW, the highest TFC with $2.83 \pm 0.06 \mathrm{mg} \mathrm{QE} / \mathrm{g}$ of DW, and a higher TAC with $11.34 \pm 0.80 \mathrm{mg}$ $\mathrm{GAE} / \mathrm{g}$ of DW. E. cilianensis and E. curvula also showed high TAC at $11.39 \pm 1.46$ and $11.77 \pm 1.38 \mathrm{mg}$ GAE/g of DW, respectively.

DPPH RSAs of all MeOH extracts were concentration-dependent and E. japonica had the highest activity with the $\mathrm{IC}_{50}$ value of $46.81 \mu \mathrm{g} / \mathrm{mL}$. E. ferruginea, E. multicaulis, and E. curvula also exhibited DPPH RSAs, whereas the activity of E. cilianensis, E. minor, and E. pilosa were below the detection limit of the assay. According to these results, the aerial parts of E. japonica and E. curvula have a high antioxidant activity, which could be related to TPC and TFC. Phenolics and flavonoids are always considered to be major contributors for the antioxidant activity of plant materials and many researchers have demonstrated the correlation between phenolics and antioxidant assays or flavonoids and antioxidant assays. As our expectation, the results showed that TPC has the positive and negative correlation with TAC $(R=0.45)$ and DPPH RSA $(R=-0.75)$, respectively (Table 3$)$. These results indicate that the antioxidant activity of the Eragrostis species depends on their phenolic content. However, TFC showed a significant correlation only with DPPH RSA $(R=-0.64)$ (Table 3$)$, supporting the hypothesis that the flavonoids present in Eragrostis species act as antioxidants by scavenging free radicals. These results might be caused by different reaction systems of antioxidants, which can exercise their protective properties at different stages of the oxidation process by different mechanisms [11]. 
Table 2. Protective effects of methanol extracts from the aerial parts of seven Eragrostis genus against Aß-induced toxicity in PC12 cells.

\begin{tabular}{lc}
\hline Eragrostis species & $\mathrm{ED}_{50}(\mu \mathrm{g} / \mathrm{mL})^{\mathrm{a}}$ \\
\hline E. ferruginea & 31.4 \\
E. cilianensis & $>100$ \\
E. minor & 17.3 \\
E. multicaulis & 34.3 \\
E. pilosa & $>100$ \\
E. japonica & 23.0 \\
E. curvula & $>100$ \\
Rosmarinic acid ${ }^{\text {b }}$ & 9.04 \\
${ }^{\mathrm{a}}$ Concentration required to achieve $50 \%$ cell viability after Aß insult; \\
${ }^{\mathrm{b}}$ positive control.
\end{tabular}

The $\mathrm{MeOH}$ extracts of the seven species were tested for neuroprotective activity against $\mathrm{A} \beta$ induced toxicity in PC12 cells (Table 2) with rosmarinic acid used as a positive control. E. ferruginea, E. minor, E. multicaulis, and E. japonica showed a neuroprotective activity against A $\beta$-induced toxicity, whereas E. cilianensis, E. pilosa, and E. curvula were inactive in the examined concentration range. $E$. minor showed the highest activity, with the $\mathrm{ED}_{50}$ value of $17.3 \mu \mathrm{g} / \mathrm{mL}$, against $\mathrm{A} \beta$-induced toxicity in PC12 cells, although it did not exhibit DPPH RSA and had the lowest TAC. E. japonica that had the highest antioxidant activity among the Eragrostis species also showed a higher neuroprotective activity $\left(\mathrm{ED}_{50}\right.$ of $23.0 \mu \mathrm{g} / \mathrm{mL}$ ) than the other Eragrostis species, except for E. minor. It was reported that neuroprotective activity against $A ß$-induced toxicity correlate with antioxidant activity against oxidative stress-induced cell death [12]. However, the present study showed that neuroprotective activity of the extracts from Eragrostis species is not related to antioxidant activity. In addition, significant correlations between all antioxidant parameters and neuroprotective activity were not observed (Table 3).

Table 3. Correlation coefficients $(R)$ between two variables in the antioxidant and neuroprotective activity of the methanol extracts from the aerial parts of seven Eragrostis species.

\begin{tabular}{lccccccc}
\hline Variables & Mean & SE & 1 & 2 & 3 & 4 & 5 \\
\hline 1. Total phenolic content & 5.27 & 0.54 & - & & & & \\
2. Total flavonoids content & 1.46 & 0.15 & $0.90^{* *}$ & - & & & \\
3. Total antioxidant capacity & 9.02 & 0.64 & $0.45^{*}$ & 0.65 & - & & \\
4. DPPH RSA & 78.11 & 5.06 & $-0.75^{* *}$ & $-0.64^{* *}$ & -0.36 & - & \\
5. Neuroprotective activity & 58.00 & 16.20 & -0.23 & -0.46 & 0.60 & 0.22 & - \\
\hline
\end{tabular}

$*$ and $* *$ mean statistically significant at $p<0.05$ and $p<0.01$, respectively.

The $\mathrm{MeOH}$ extract of E. japonica that showed the most significant activity in this study was used to isolate compounds related to antioxidant or neuroprotective activities. Three metabolites were isolated and then identified as isoorientin (1) [13], isovitexin (2) [14], and caffeic acid (3) [15] that have antioxidant and neuroprotective activities (Figure 1) [16-18]. Compound $\mathbf{1}$ and $\mathbf{2}$ were investigated their DPPH RSA and compound 1 showed significant free radical scavenging activity [19]. These compounds were isolated from Eragrostis genus for the first time. Antioxidant or neuroprotective activities of E. ferruginea and $E$. japonica might be mediated by the previously reported compounds, tricin, ageconyflavone A, nectandrin B, and 4-ketopinoresinol [5] and by the isolated compounds in this study, isoorientin (1), isovitexin (2), and caffeic acid (3), respectively. Antioxidant activity of E. curvula also might be induced by the previously reported flavones, tricin and violanthin [20]. However, it remains unknown whether these compounds are present in other Eragrostis species, therefore, further studies are required to isolate and identify the potentially antioxidant or neuroprotective compounds in other Eragrostis species. 


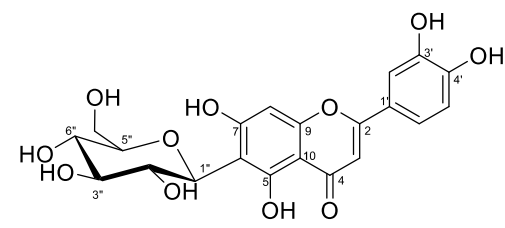

1

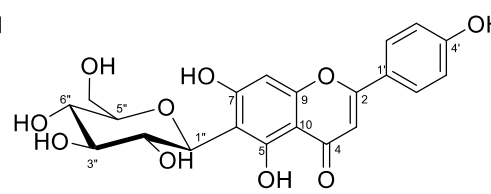

2<smiles>O=C(O)C=Cc1ccc(O)c(O)c1</smiles>

3

Figure 1. Structures of compounds 1 - 3 isolated from Eragrostis japonica.

Eragrostis Wolf is the largest genus within the subfamily Chloridoideae of the Poaceae and has about 350 species, of which only 3 species have been studied for flavonoids: E. ferruginea, E. curvula and E. tef [5, 20-21]. These 3 species showed different flavonoids profiles except tricin. E. ferruginea has been reported to contain 7-demethylageconyflavone A, ageconyflavone A and tricin [5]. E. curvular contained tricin and violanthin [20] and E. tef has been shown to contain naringenin, naringenin-4'-methoxy-7-Orhamnoside, eriodictyol-3', 7-dimethoxy-4'-O-glucoside and isorhamnetin-3-O-rhamnoglucoside [21]. The isolated flavonoids of E. japonica also differ from the species in that it only contained isoorientin and isovitexin. According to these results the distinct chemotaxonomic relationship was not observed among these species. The further research on the flavonoids in other Eragrostis species would be useful to find potential sources of natural antioxidants or neuroprotectants as well as chemotaxonomic study in Eragrostis genus.

Seven Eragrostis species were studied in this work to establish whether they could be potential sources of natural antioxidants or neuroprotectants. All species exhibited antioxidant or neuroprotective activities and especially $E$. japonica showed the highest TPC and TFC values, as well as TAC and DPPH RSA, with the second-highest neuroprotective value. The isolated compounds from E. japonica in this study were shown to have a strong antioxidant and neuroprotective activities in previous reports. In conclusion, our results demonstrate that the aerial parts of select Eragrostis species have the potential of use as antioxidants or neuroprotectants and, among them, particularly E. japonica could be a valuable source of specific flavonoid-type antioxidants that can be used as neuroprotective agents.

\section{Acknowledgments}

This study was supported by the National Research Foundation of Korea grant NRF2013R1A/1 A2010178 and we thank Thomas Roach (University of Innsbruck) for helping with English.

\section{ORCID}

Chae Sun Na: $\underline{0000-0002-7936-2121}$

Min Ju Lee: 0000-0003-0965-4724

Seong Su Hong: 0000-0002-2498-7546

Yun-Hyeok Choi: 0000-0002-0909-0677

Jae-Eun Lee: 0000-0001-7481-6123

So-Young Park: 0000-0002-1065-6746

Yong Ho Lee: 0000-0002-8714-3746

Sun Hee Hong: 0000-0001-7581-0604

\section{References}

[1] B. Boka, A.Z. Woldegiorgis, and G.D. Haki (2013). Antioxidant properties of Ethiopian traditional bread (Injera) as affected by processing techniques and tef grain (Eragrostis tef (Zucc.)) varieties, Can. Chem. Trans. 1, 7-24. 
[2] S.F. Forsido, H.P.V. Rupasinghe and T. Astatkie (2013). Antioxidant capacity, total phenolics and nutritional content in selected Ethiopian staple food ingredients, Int. J. Food Sci. Nutr. 64, 915-920.

[3] N.S.N. Sebastião, I.J.S. Cordeiro, A.F. Santos, J.F. Gaspar, C. Martins, J. Rueff, et al. (2010). 8,15Epoxylabdane and norlabdane diterpenoids from Eragrostis viscosa, Phytochemistry 71, 798-803.

[4] K. Nishiya, T. Kimura, K. Takeya, H. Itokawa and S.R. Lee (1991). Diterpenoids from Eragrostis ferruginea, Phytochemistry 30, 2410-2411.

[5] C.S. Na, S.S. Hong, Y.H. Choi, Y.H. Lee, S.H. Hong, J.Y. Lim, et al. (2010). Neuroprotective effects of constituents of Eragrostis ferruginea against A beta-induced toxicity in PC12 cells, Arch. Pharm. Res. 33, 999-1003.

[6] A. Ismail, Z.M. Marjan and C.W. Foong (2004). Total antioxidant activity and phenolic content in selected vegetables, Food Chem. 87, 581-586.

[7] C.C. Chang, M.H. Yang, H.M. Wen and J.C. Chern (2002). Estimation of total flavonoid content in propolis by two complementary colorimetric methods, J. Food Drug Anal. 10, 178-182.

[8] S.M. Islam, K.T. Ahmed, M.K. Manik, M.A. Wahid and C.S. Kamal (2013). A comparative study of the antioxidant, antimicrobial, cytotoxic and thrombolytic potential of the fruits and leaves of Spondias dulcis, Asian Pac. J. Trop. Biomed. 3, 682-691.

[9] C. Desmarchelier, M.J.N. Bermudez, J. Coussio, G. Ciccia and A. Boveris (1997). Antioxidant and prooxidant activities in aqueous extracts of Argentine plants, Int. J. Pharmacogn. 35, 116-20.

[10] J.H. Chen and C.T. Ho (1997). Antioxidant activities of caffeic acid and its related hydroxycinnamic acid compounds, J. Agr. Food Chem. 45, 2374-2378.

[11] E.N. Frankel and A.S. Meyer (2000). The problems of using one-dimensional methods to evaluate multifuctional food and biological antioxidants, J. Sci. Food Agric. 80, 1925-1941.

[12] C. Behl, T. Skutella, F. Lezoualch, A. Post, M. Widmann, C.J. Newton and F. Holsboer (1997). Neuroprotection against oxidative stress by estrogens: Structure-activity relationship, Mol. Pharmacol. 51, 535-541.

[13] S.W. Chang, K.H. Kim, I.K. Lee, S.U. Choi, S.Y. Ryu and K.R. Lee (2009). Phytochemical Constituents of Bistorta manshuriensis, Nat. Prod. Sci. 15, 234-240.

[14] B.C.K. Hirota, C.M.S. Miyazaki, C.A. Mercali, M.C. Verdam, M. Kalegari, C. Gemin et al. (2012). Cglycosyl flavones and a comparative study of antioxidant, hemolytic and toxic potential of Jatropha multifida leaves and bark, Int. J. Phytomed. 4, 1-5.

[15] Y.X. Li, W.T. Qiao and K. Yuan (2011). Isolation and structural elucidation of chemical constituents of Mussaenda hainanensis Merr, J. Med. Plants Res. 5, 1459-1465.

[16] C.C. Guimaraes, D.D. Oliveira, M. Valdevite, A.L.F. Saltoratto, S.I.V. Pereira, S.C. Franca et al., 2015. The glycosylated flavonoids vitexin, isovitexin, and quercetrin isolated from Serjania erecta Radlk (Sapindaceae) leaves protect PC12 cells against amyloid-beta (25-35) peptide-induced toxicity, Food Chem. Toxicol. 86, 88-94.

[17] D. Sul, H.S. Kim, D. Lee, S.S. Joo, K.W. Hwang and S.Y. Park (2009). Protective effect of caffeic acid against beta-amyloid-induced neurotoxicity by the inhibition of calcium influx and tau phosphorylation, Life Sci. 84, 257-262.

[18] L. Yu, S. Wang, X. Chen, H. Yang, X. Li, Y. Xu and X. Zhu (2015). Orientin alleviates cognitive deficits and oxidative stress in Aß (1-42)-induced mouse model of Alzheimer's disease, Life Sci. 121, 104-109.

[19] K.R. Joshi, H.P. Devkota, T. Nakamura, T. Watanabe and S. Yahara (2015). Chemical constituents and their DPPH radical scavenging activity of Nepalese crude drug Begonia picta, Rec. Nat. Prod. 9, 446450 .

[20] M. Kaneta and N. Sugiyama (1972). Identification of flavone compounds in eighteen Gramineae Species, Agr. Biol. Chem. 37, 2663-2665.

[21] T.S. El-Alfy, S.M. Ezzat and A.A. Sleem (2012). Chemical and biological study of the seeds of Eragrostis tef (Zucc.) Trotter, Nat. Prod. Res. 26, 619-629.

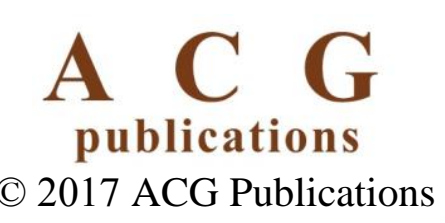

